\section{Perfil da produção bibliográfica em Ciências Sociais e Humanas em Saúde e a percepção de pesquisadores: avanços, limites e desafios}

\author{
Profile of the research production in Human \\ and Social Sciences in Health and researchers' \\ perceptions: strides, limits, and challenges
}

\section{Perfil de la producción bibliográfica en Ciencias Sociales y Humanas en Salud y la percepción de investigadores: avances, límites y desafíos}

Jorge Alberto Bernstein Iriart 1 Leny Alves Bomfim Trad 1

\title{
Resumo
}

Este artigo tem por objetivo traçar o perfil da produção científica de docentes da área das Ciências Sociais e Humanas em Saúde (CSHS) nos programas de pós-graduação em Saúde Coletiva, privilegiando o período de 2004 a 2012 (três triênios da avaliação da Coordenação de Aperfeiçoamento de Pessoal de Nivel Superior - avaliação CAPES), assim como a visão dos pesquisadores sobre o processo de publicação e seus principais desafios. Foram utilizados, como fontes de dados, os cadernos de avaliação da CAPES de 2004 a 2012 e a produção bibliográfica registrada no Currículo Lattes de 176 professores da área de CSHS, credenciados nos programas de pós-graduação em Saúde Coletiva no mesmo período, extraída por meio da ferramenta ScriptLattes. Foram também utilizados questionários on-line, respondidos de forma anônima por 59 pesquisadores, e entrevistas semiestruturadas em profundidade, realizadas com 19 pesquisadores de diferentes gerações, incorporando, também, por meio de ambas as fontes, a percepção dos atores sobre a situação mais recente da área. A produção científica em CSHS teve aumento de 60,49\% na produção de artigos. No período estudado, 25,22\% da produção foi publicada na forma de livros e 62,36\% na forma de artigo. O número de pesquisadores, no entanto, não aumentou no período, o que pode estar relacionado à dificuldade de credenciamento nos programas de pós-graduação por conta das crescentes exigências de produção. Os pesquisadores da área mostraram insatisfação com vários aspectos do processo de publicação científica e com os efeitos da avaliação CAPES, entre os quais, o incentivo ao "produtivismo" e a desconsideração das diferenças nos tempos e nos processos de produção entre as áreas, o que pode vir a comprometer a própria interdisciplinaridade que caracteriza a Saúde Coletiva.

Ciências Sociais; Ciências Humanas; Pesquisa; Avaliação de Programas e Instrumentos de Pesquisa; Indicadores de Produção Científica

\author{
Correspondência \\ J. A. B. Iriart \\ Instituto de Saúde Coletiva, Universidade Federal da Bahia. \\ Rua Basílio da Gama s/n, 2o andar, Salvador, BA \\ 40110-040, Brasil. \\ iriart@ufba.br \\ 1 Instituto de Saúde Coletiva, Universidade Federal da Bahia, \\ Salvador, Brasil.
}




\section{Introdução}

A Saúde Coletiva passou por um processo de grande expansão ao longo da última década com aumento exponencial no número de programas de pós-graduação na área e concomitante aumento da produção científica 1. No âmbito dessa produção, interessa aqui destacar o aporte das Ciências Sociais e Humanas em Saúde (CSHS) cujos estudos têm contribuído historicamente para o avanço do conhecimento sobre a dimensão social da saúde e, certamente, para a difusão e o aperfeiçoamento de seus referenciais teóricos e metodológicos 2.

Trabalhos que procuraram traçar um panorama da produção científica em CSHS têm evidenciado sua expansão e consolidação, refletidos no volume crescente de publicações, assim como de trabalhos apresentados em congressos 3,4,5,6. Além da presença significativa de publicações autorais ou com reduzido número de coautores, mantém-se, na área, a tradição da publicação de livros.

Por outro lado, tem sido recorrente, entre os intelectuais das CSHS, as críticas à imposição do modelo produtivista, notadamente, por meio do sistema da avaliação da pós-graduação brasileira. No caso da Saúde Coletiva, à medida que tal sistema passou a privilegiar a dimensão quantitativa (número de artigos publicados) e os indicadores bibliométricos, como fator de impacto e índice $\mathrm{h}$ (mais elevados em revistas internacionais da área biomédica), favoreceu o modo de produção típico da Epidemiologia, contribuindo assim para produzir iniquidades no campo 3,7,8,9,10.

Considerando, por certo, o caráter indutor da avaliação, convém seguir monitorando seus efeitos para a produção da área, traçando tendências e identificando, por meio dela, o movimento dos seus atores. Interessa ainda abrir espaço para a escuta desses pesquisadores, levando em conta o processo mais recente de ampliação e renovação de quadros. Neste artigo, procura-se traçar o perfil da produção científica nos programas de pós-graduação em Saúde Coletiva na área das CSHS, privilegiando o período de 2004 a 2012, que corresponde a três triênios da avaliação da avaliação da Coordenação de Aperfeiçoamento de Pessoal de Nível Superior (CAPES), assim como a visão dos pesquisadores da área sobre o processo de publicação e seus principais desafios. Esse segundo tópico contempla um momento mais recente, uma vez que a escuta aos atores da área se deu entre 2016-2017.

Além do diálogo com autores do campo, cujos trabalhos contemplam análises primorosas sobre o fenômeno em foco, destacando-se, dentre outros, Russo \& Carrara 7, Camargo Jr. et al. 8, Loyola 9 e Luz 10, este trabalho se nutriu, em alguma medida, de aportes da Teoria Ator-Rede 11,12, uma abordagem que privilegia a descrição dos rastros deixados pelos atores humanos (artigos e outras formas de publicação se encaixariam nessa categoria) e não humanos (artefatos, tecnologias etc.), assim como a interação ou as múltiplas associações que se desenvolvem entre eles na prática científica cotidiana.

\section{Metodologia}

Trata-se de um recorte de um estudo mais amplo intitulado Perfil e Contribuições das Ciências Humanas e Sociais no Campo da Saúde Coletiva: Pesquisa, Ensino e Extensão - Foco nos Programas de Pós-graduação, financiado pelo edital Universal 2013 do Conselho Nacional de Desenvolvimento Científico e Tecnológico $(\mathrm{CNPq})$ e que procurou traçar um retrato (dinâmico) da área de CSHS, considerando sua inserção e atuação na pós-graduação em Saúde Coletiva no Brasil.

No eixo da produção bibliográfica em CSHS, objeto deste artigo, foram mobilizadas as seguintes fontes de dados: os cadernos de avaliação da CAPES (Produção Bibliográfica e Corpo Docente) em três triênios, entre 2004-2012; a produção bibliográfica registrada no Currículo Lattes (http://lattes. cnpq.br/) de 176 professores da área de CSHS, credenciados como permanentes ou colaboradores dos programas de pós-graduação em Saúde Coletiva no mesmo período, extraída por meio da ferramenta ScriptLattes (http://scriptlattes.sourceforge.net/). O ScriptLattes é um projeto de software livre, idealizado por Jesús Mena-Chalco e Roberto Cesar-Jr, em 2005, que permite o download automático do currículo Lattes em formato HTML, a compilação de listas de produções e o tratamento apropriado das produções duplicadas e similares. Vale notar que a implantação da Plataforma Sucupira se deu em momento posterior aos três triênios analisados na pesquisa.

Foram também utilizados questionários on-line, respondidos de forma anônima por 59 pesquisadores (o instrumento foi enviado para os 176), e entrevistas semiestruturadas em profundidade, 
realizadas, via Skype (https://www.skype.com/pt-br/), com 19 pesquisadores de diferentes gerações (informantes-chave). Esses dois últimos instrumentos abordaram, no tocante à produção bibliográfica, questões relacionadas ao modo de produzir (e publicar) e os principais desafios nesse processo.

Os critérios estabelecidos para identificar vinculação ou aderência à área de CSHS por parte dos docentes que compuseram a amostra ampliada foram os seguintes: (a) revelar posição de liderança na área, demonstrada, por exemplo, pela atuação como coordenador ou membro de Grupos Temáticos ou Comissões da Associação Brasileira de Saúde Coletiva (Abrasco) ou outras comissões de interesse específico da área; (b) prática de ensino, pesquisa e extensão associada à área; (c) formação em Ciências Sociais e Humanas (na graduação e/ou pós-graduação); (d) estar vinculado aos programas de pós-graduação, ainda que como colaboradores; (e) estar credenciado na condição de permanente ou colaborador em programas de pós-graduação em Saúde Coletiva em, pelo menos, um dos três triênios que a pesquisa contemplou. É importante observar, no entanto, que nem sempre as fronteiras entre as áreas são bem definidas, e que alguns pesquisadores transitam e atuam em mais de uma área.

O recorte geracional, um dos critérios adotados na seleção dos informantes-chave que participaram das entrevistas em profundidade (levou-se em conta também a representação regional e institucional da amostra), seguiu a lógica proposta por Ianni et al. 13 que distingue as gerações segundo a inserção ou protagonismos dos sujeitos em três momentos do campo: constituição, institucionalização e consolidação do campo da Saúde Coletiva e da área de CSHS. Utilizou-se uma tipologia correlata para indicar o pertencimento geracional dos interlocutores, cujos depoimentos foram citados no artigo, por meio dos códigos GH, GI, GN - geração histórica, intermediária, nova - antecedidos da letra Q quando extraídos dos questionários on-line (questões abertas).

Para a análise do perfil da publicação na área, foram considerados os seguintes indicadores: tipo de publicação (artigos, livros, capítulos de livro), área de conhecimento, veículo e status (Qualis da revista em 2012 e 2016), participação em publicações (coautorias), perfil de composição na autoria (grau de envolvimento de (ex)orientandos, pesquisadores do mesmo grupo de pesquisa e/ou programas, pesquisadores externos e internacionalização). No tratamento dos dados provenientes das questões abertas do questionário on-line, assim como das narrativas advindas das entrevistas, utilizou-se a análise de conteúdo temática.

O projeto foi aprovado pelo Comitê de Ética em Pesquisa do Instituto de Saúde Coletiva/Universidade Federal da Bahia (parecer 708.494), e foram seguidas todas as recomendações da Resolução CNS no 466/2012 e da Resolução CNS no 510/2016.

\section{Resultados e discussão}

\section{Volume e perfil geral da produção na área de CSHS}

O número total de artigos e capítulos de livro publicados nos três triênios (2004-2006; 2007-2009 e 2010-2012) alcançou 6.584 produtos, sendo 4.106 artigos (62,36\%), 2.204 capítulos de livros (33,47\%) e 274 livros autorais (monografias) (4,16\%) (Tabela 1). Os dados produzidos por meio das respostas ao questionário on-line com pesquisadores da área $(\mathrm{n}=59)$ mostraram dados similares, com $61 \%$ da produção acadêmica publicada em periódicos científicos. Comparando-se a produção total de artigos no triênio de 2004-2006 (1.020 artigos) com a produção no triênio de 2010-2012 (1.637), houve aumento de 60,49\%. A produção de capítulos de livros no triênio de 2004-2006 alcançou 670 capítulos. No triênio de 2010-2012, subiu para 839 capítulos (aumento de 25,22\%). A produção de livros autorais (monografias) passou de 89 no triênio de 2004-2006 para 95 no triênio de 2010-2012, aumento de 6,74\% (Tabela 2 e Figura 1).

Os resultados atestam o dinamismo na produção científica na área de CSHS com aumento significativo na produção científica em artigos e livros (60,49\% e 25,22\% respectivamente) entre os triênios de 2004-2006 e de 2010-2012. A tendência de aumento contínuo das publicações na área já havia sido apontada por Minayo 14. A maior parte da produção científica da área foi publicada na forma de artigos (62,36\%), o que vai ao encontro de pesquisa realizada por Viacava \& Ramos 15, publicada no fim da década de 1990, cujos resultados já indicavam que 60\% das publicações e/ou produção acadêmica da área foram feitas em periódicos. 


\section{Tabela 1}

Artigos, capítulos de livros e monografias publicados na área de Ciências Sociais e Humanas de Saúde. Brasil, 2004 a 2012.

\begin{tabular}{lcc}
\hline Produção bibliográfica & $\mathbf{n}$ & $\%$ \\
\hline Artigos & 4.106 & 62,36 \\
Capítulo de livros & 2.204 & 33,47 \\
Monografias & 274 & 4,16 \\
Total & 6.584 & 100,00 \\
\hline
\end{tabular}

Fonte: elaboração própria usando dados da Plataforma Lattes (http://lattes.cnpq.br/).

Tabela 2

Percentual de aumento da produção de artigos, capítulos de livros e monografias publicados na área de Ciências Sociais e Humanas de Saúde entre 2004-2006 e 2010-2012.

\begin{tabular}{lccc}
\hline & $\mathbf{2 0 0 4 - 2 0 0 6}$ & $\mathbf{2 0 1 0 - 2 0 1 2}$ & \% \\
\hline Artigos & 1.020 & 1.637 & 60,49 \\
Capítulo de livros & 670 & 839 & 25,22 \\
Monografias & 89 & 95 & 6,74 \\
\hline
\end{tabular}

Fonte: elaboração própria usando dados da Plataforma Lattes (http://lattes.cnpq.br/).

\section{Figura 1}

Produção bibliográfica na área de Ciências Sociais e Humanas de Saúde entre 2004 e 2012.



Fonte: elaboração própria usando dados da Plataforma Lattes (http://lattes.cnpq.br/). 
A produção em livros (coletâneas e monografias), que era uma característica das CSHS, ainda possui uma dimensão relevante no conjunto bibliográfico da área $(37,64 \%)$. Observa-se, no entanto, que, apesar de a produção em livros ter aumentado $25,22 \%$ no período, o aumento percentual da produção em artigos foi 17,25\% superior, apontando para uma possível tendência de diminuição da participação da produção em livros na produção total da área. Ressalta-se, ainda, o pequeno aumento (6,31\%) na publicação de livros autorais, o que também pode indicar tendência de perda de espaço dessa forma de produção no conjunto da área. É possível que essa tendência seja reflexo da exigência de produtividade presente na avaliação CAPES que não deixa espaço para a produção de obras autorais que demandam maior tempo no processo de elaboração, reflexão e amadurecimento de novas ideias e aportes teóricos e metodológicos.

É importante observar, também, que o aumento de 60,49\% na produção científica em artigos no período analisado não foi acompanhado do aumento quantitativo do número de pesquisadores credenciados nos programas de pós-graduação da área, o qual permaneceu praticamente estável ao longo dos três triênios: 2004-2006 (164); 2007-2009 (165) e 2010-2012 (163).

Esse resultado sugere que o aumento da produção científica ocorreu por aumento da produtividade dos pesquisadores, e não por incorporação de um contingente maior de pesquisadores na área. $O$ número quase constante de pesquisadores ao longo de 12 anos mostra que novos pesquisadores estão apenas substituindo pesquisadores que se aposentam, sem crescimento do contingente de docentes que atuam no quadro permanente dos programas de pós-graduação. Esse fato revela-se ainda mais surpreendente e preocupante quando se considera o aumento exponencial do número de programas de pós-graduação em Saúde Coletiva ao longo do período analisado.

Uma explicação possível para esse achado é a dificuldade crescente para credenciamento dos pesquisadores da área de CSHS nos programas de pós-graduação por conta dos critérios de produtividade cada vez mais exigentes da avaliação CAPES. Iriart et al. 3 , utilizando dados da avaliação trienal 2010-2012, mostram como as medianas de produção das três áreas (Epidemiologia; CSHS; e Política, Planejamento e Gestão) são significativamente diferentes, tornando muito mais difícil para os pesquisadores das subáreas CSHS e Política, Planejamento e Gestão alcançarem os parâmetros estabelecidos para ter sua produção classificada como muito boa. Dado que o valor da mediana da área é frequentemente utilizado por coordenadores de programas para pautar os critérios de credenciamento de docentes somado à dificuldade de estimar a pontuação da produção em livros, os pesquisadores da área de CSHS têm maior dificuldade de se manter credenciados e se torna muito difícil para os novos pesquisadores ingressarem no sistema. O estudo de Iriart et al. 3 mostra que os docentes credenciados como permanentes nos programas de pós-graduação na área das CSHS na avaliação trienal de 2013 representavam apenas 16,8\% dos docentes permanentes dos programas da Saúde Coletiva.

Para análise do perfil da publicação em artigos, utilizou-se, inicialmente, o Qualis Periódicos da CAPES do último triênio pesquisado (2010-2012). Em 2016, a coordenação da área da Saúde Coletiva promoveu alteração no Qualis visando tornar mais equânime a classificação das revistas entre as áreas de Epidemiologia, CSHS e Políticas de Saúde. Para efeito de comparação entre os dois Qualis, procedeu-se também a reclassificação dos periódicos a partir do Qualis CAPES (2013-2016).

Utilizando-se o Qualis de 2012, dos 4.106 artigos publicados nos três triênios, 54 são Qualis A1 (1,31\%); 475, A2 (11,56\%); 970, Qualis B1 (23,62\%); 763, B2 (18,58\%); 405, B3 (9,86\%); 686, B4 (16,7\%); 96, B5 (2,33\%); e 171, C (4,16\%); sendo 486 com Qualis não identificado (11,83\%) (Tabela 3). Observase que $55,09 \%(\mathrm{n}=2.262)$ da produção em artigos foi publicada em revistas de Qualis elevado (B2 ou superior), sendo 529 (12,88\%) produção internacional (Qualis A1 e A2).

Quando se utiliza o Qualis de 2016, constata-se pequeno aumento (2,99\%) no percentual de artigos classificados nos estratos de Qualis elevado (B2 ou superior). O novo Qualis ocasionou um aumento de 3,38\% nas revistas classificadas como internacionais (A1 e A2). A maior alteração, no entanto, ocorreu nos estratos B1 (aumento de 6,65\%) e B2 (diminuição de 7,04\%) (Tabela 3).

Os resultados mostram que a área concentra sua publicação em revistas de Qualis B2 ou superior (55,09\%). O fato de que apenas 12,87\% da produção da área se situa nos estratos A1 e A2 (Qualis 2012) mostra que a internacionalização da produção científica ainda é reduzida. Esse achado tem que ser relativizado, no entanto, dado que uma queixa frequente dos pesquisadores de CSHS é o pequeno leque de revistas internacionais da área que são bem classificadas com Qualis A1 ou A2. Por conta dos indicadores utilizados como critério de classificação (fator de impacto e índice h), as revistas da 
Tabela 3

Qualis CAPES dos artigos publicados na área de Ciências Sociais e Humanas de Saúde entre 2004 e 2012.

\begin{tabular}{lcccc}
\hline & Qualis 2012 & \% & Qualis 2016 & $\%$ \\
\hline A1 & 54 & 1,31 & 63 & 1,53 \\
A2 & 475 & 11,56 & 605 & 14,73 \\
B1 & 970 & 23,62 & 1.243 & 30,27 \\
B2 & 18,58 & 474 & 11,54 \\
B3 & 763 & 9,86 & 424 & 10,32 \\
B4 & 405 & 2,70 & 184 & 5,89 \\
B5 & 686 & 4,33 & 81 & 4,48 \\
C & 96 & 11,16 & 790 & 1,97 \\
Sem Qualis & 171 & 4.106 & 19,24 \\
Total & 486 & 100,00 & 100,00 \\
\hline
\end{tabular}

Fonte: elaboração própria usando dados da Plataforma Lattes (http://lattes.cnpq.br/).

área tendem a ser mal classificadas. Ao não classificar revistas importantes de CSHS nos estratos A1 e A2, a avaliação CAPES termina por não cumprir seu papel indutor, pois, em termos de pontuação, não compensa para os autores publicar em uma revista internacional que não será reconhecida nos estratos A. De fato, revistas importantes da Sociologia, Antropologia ou Psicologia que, em suas respectivas áreas, ocupam os extratos mais elevados (A1, A2) são classificadas na Saúde Coletiva entre B1 e B2. Pode-se questionar ainda se o baixo percentual de publicações em A1 e A2 não reflete também uma recusa de engajamento, por parte de pesquisadores da área, em um diálogo internacional em condições de subalternidade, em uma relação vista, por alguns, como "colonizada”. Para Madel Luz 10 (p. 46), o Qualis Periódicos tornou-se um "dogma sobre o qual repousa a classificação hierarquizada da produção dos pesquisadores e de seus programas”, sobretudo, se considerarmos que ele se baseia em bases catalográficas, geralmente privadas, para as quais a "excelência" é definida apenas pelo índice de citações/impacto das revistas 10. Vários pesquisadores da área têm criticado o sistema de avaliação e mostrado como ele pode provocar distorções em áreas interdisciplinares como a Saúde Coletiva 3,8,16.

A partir dos dados extraídos do Currículo Lattes, as dez revistas em que mais ocorreu a produção da área foram: Ciência eł Saúde Coletiva (480), Cadernos de Saúde Pública (329), Interface (183), Physis (149), Revista de Saúde Pública (113), Saúde e Sociedade (104), Revista Brasileira de Educação Médica (78), História, Ciências, Saúde-Manguinhos (70), Saúde em Debate (49) e Revista Latino-Americana de Enfermagem (41). Observa-se que, das dez revistas, nove são da área da Saúde Coletiva e uma da Enfermagem. Os dados do questionário on-line $(\mathrm{n}=59)$ mostram que $67,8 \%(\mathrm{n}=40)$ dos artigos foram publicados em periódicos da área da Saúde Coletiva; 28,8\% $(\mathrm{n}=17)$ na área de Ciências Humanas e 3,4\% $(\mathrm{n}=2)$ em outras áreas.

Os resultados apontam que a produção da área é publicada majoritariamente em revistas da área da Saúde Coletiva. Há produção significativa, no entanto, veiculada na área de Ciências Humanas apesar dos critérios de avaliação CAPES não favorecerem a publicação em outras áreas por conta dos critérios distintos de classificação das revistas.

No que se refere ao padrão de autoria, mais especificamente a quantidade de autores por título, com base na análise da produção em artigos nos Currículos Lattes ( $\mathrm{n}=3.987 ; 2004-2012)$, observase que $26,42 \%$ dos artigos tiveram um único autor (1.051); 26,53\%, dois autores (1.058); 17,80\%, três autores (710); 10,48\%, quatro autores (418); e 18,81\%, cinco ou mais autores (750). Constata-se, portanto, que o perfil de autoria da área se caracteriza pelo pequeno número de autores e coautores, em que 52,95\% dos artigos possuem até dois autores, e 70,75\%, até três autores. Esses achados contrastam com o padrão de coautoria na Epidemiologia em que estudo de Camargo Jr. et al. 8 apontou que 75,3\% dos estudos tinham mais de três autores.

Minayo 14 traz em sua pesquisa que, no período analisado por ela (1998-2000), houve queda na proporção de única autoria na área da Saúde Coletiva, que era de 64\% no primeiro triênio analisado, 
chegando a $22 \%$ no terceiro triênio. Para a autora, esse fato significativo nos mostra uma transformação de padrão de pesquisas individuais para multicêntricas, em rede ou em parceria. $\mathrm{O}$ resultado do perfil de composição das autorias das publicações nas respostas ao questionário on-line $(\mathrm{n}=59)$ sugere que o crescimento da coautoria pode ter ocorrido também pelo aumento da produção entre orientador e orientando, já que $89,8 \%$ dos pesquisadores informaram publicar em coautoria com seus orientandos. O padrão de coautoria em publicação conjunta com os orientandos difere do observado na área das Ciências Sociais, que pratica a autoria única, e possivelmente é influenciado pelas exigências de produção da avaliação CAPES para docentes e discentes.

Quanto à publicação com pesquisadores de outros programas, $71,2 \%$ dos pesquisadores entrevistados (42) no questionário on-line afirmaram que publicam frequentemente ou sempre com pesquisadores externos ao programa, indicando a existência de uma boa colaboração entre grupos de pesquisa na área. Apenas, 1,7\% afirmou nunca ter publicado com pesquisadores de outros programas de pós-graduação, e 57,4\% dos pesquisadores (respondentes do questionário on-line) declararam estar inseridos em redes de pesquisa nacional e $35,2 \%$ em redes internacionais. Por outro lado, é importante lembrar que pertencer a uma rede de pesquisa nem sempre se traduz em publicações conjuntas 17 . Isso explicaria, por exemplo, o fato de o percentual de publicação em coautoria com pesquisadores estrangeiros na enquete on-line ter sido menor $(22,4 \%, \mathrm{n}=13)$. Observa-se, ainda, que $52,5 \%$ dos autores não publicaram nenhum artigo em revistas estrangeiras no último triênio.

\section{A publicação em CSHS - limites, avanços e desafios na visão dos pesquisadores}

O tema da publicação, abordado em alguns tópicos do questionário on-line dirigido aos pesquisadores, foi especialmente problematizado durante as entrevistas, não sendo observadas diferenças muito significativas entre as três gerações contempladas no estudo.

Partindo de uma avaliação mais global acerca dos critérios adotados pelos periódicos de diferentes áreas para aceitação/rejeição de artigos, encontramos os seguintes resultados no questionário on-line: $37,3 \%$ dos pesquisadores consideraram regular; $30,5 \%$, bom; $25,4 \%$, ruim; e 6,8 , muito bom, prevalecendo, portanto, uma avaliação negativa.

Entre aqueles que consideraram ruim ou regular os ditos critérios, destacam-se, de uma parte, argumentos centrados em aspectos metodológicos, mais especificamente nas dificuldades de publicar os produtos de pesquisas qualitativas cujos enfoques demandam um tratamento mais denso:

"Os artigos são avaliados por critérios científicos e requisitos que não levam em consideração a especificidade da pesquisa social e da metodologia qualitativa" (QGN2).

"Há restrições ainda, em alguns periódicos, de entender e/ou aceitar métodos compreensivo-interpretativos em estudos empíricos, assim como em validar academicamente estudos de natureza crítico-reflexiva" (QGH4).

"Os critérios de aceitação e exigências das revistas de Saúde Coletiva/Pública para os artigos das áreas de CSHS são ultrajantes, pois, em geral, os editores imprimem a lógica da Epidemiologia e Bioestatística ao conjunto dos artigos apresentados, e as exigências feitas aos autores de pesquisas qualitativas são muito maiores e mais complexas que artigos com lógica quantitativa" (QGI5).

De outra parte, foram recorrentes comentários que traziam à tona as controvérsias e os embates com avaliadores ad hoc e editores em torno da questão da "cientificidade", abrangendo questões de ordem teórica ou metodológica ou relativas aos próprios objetos de pesquisa:

"Em geral, os periódicos têm pouca abertura para abordagens intertransdisciplinares. Por quatro vezes, tivemos artigos recusados em periódicos de Saúde Coletiva sob o argumento de que não pertenciam àquele campo..." (QGI35).

Nas entrevistas, foram reiteradas as dificuldades apontadas nos questionários, aprofundando-se a crítica em torno do reconhecimento limitado no campo da Saúde Coletiva da relevância e pertinência de temas e enfoques inerentes às CSHS. Ser ou não ser ciência - eis a questão, poderia ser uma boa síntese do tom que prevaleceu nas narrativas dos entrevistados:

"As nossas revistas (...) muitas delas, mesmo aquelas que recebem os textos das Ciências Sociais, a gente só tem alguns textos que é possivel mandar, outros não (...) até tamanho que é necessário pra escrevê-los, pela estética literária, às vezes se vocêe escreve de um jeito, já não é aceito de jeito nenhum, porque parece que você não tá fazendo ciência, você tá fazendo literatura. É exatamente o contrário, às vezes, você precisa de um estilo literário pra você conseguir passar aquela... ideia principal que, você tá querendo veicular..." (GI6). 
Com respeito aos critérios formais de apresentação de texto, observa-se que o tamanho do manuscrito ou o limite no número de palavras foram um dos pontos mais enfatizados nos questionários. Os fragmentos abaixo ilustram bem as visões esboçadas:

"Na Saúde Coletiva, os periódicos forçam os cientistas sociais a se encaixarem num modelo bastante "duro", sendo necessário ter um certo padrão ou formato de texto. Algumas revistas exigem seções específicas, prenomeadas e padronizadas" (QGN25).

"Na saúde, os artigos são, muitas vezes, mais enxutos e concisos, o que dificulta a apresentação de alguns dados quando se trata de pesquisa com abordagem etnográfica, pois a densidade da descrição pode se perder" (QGI18).

Foram consensuais, entre os entrevistados, a preocupação e a insatisfação frente ao reduzido número de revistas nos estratos superiores do Qualis da Saúde Coletiva que publicam artigos da área de CSHS. O espectro das revistas bem qualificadas na área de Saúde Coletiva, nas quais os pesquisadores brasileiros das CSHS teriam maiores chances de publicar, torna-se ainda mais limitado se levarmos em conta as dificuldades associadas à publicação em revistas estrangeiras. Dentre as dificuldades, o custo de submissão e/ou publicação foi o mais referido. Mas, sem dúvida, as questões mais substanciais, conforme se apreende dos relatos de alguns entrevistados, remetem ao processo de avaliação (aceitação/rejeição) dos manuscritos e às dimensões culturais e políticas que elas ensejam:

"A nossa publicação fora do Brasil por conta de uma linguagem que é muito mais específica do nosso campo, que é muito mais nacional, muito mais local, é muito mais difícil do que professores da Epidemiologia, por exemplo, que eles têm uma linguagem universal, matemática, científica..." (GI9).

"Então se você estuda questões mais relacionadas à brasilidade, à questão local, ou, por exemplo, eu trabalho com análise de discurso, então a língua pra mim é fundamental, é minha matéria de trabalho. Eu poderia mandar traduzir? Eu poderia, mas eu ia perder incrivelmente todo o assentamento da reflexão que é a variação semântica. Você vai traduzir, você vai pra uma outra gramática, pra uma outra semântica, pra uma outra sintaxe, não é só uma questão de tradução. Então, essas peculiaridades são tornadas desigualdades nesse mercado da produtividade" (GI7).

Cabe enfatizar aqui os desafios relativos à visibilidade da produção na área, considerando tanto sua forte conexão com contextos locais ou regionais quanto a concentração em publicações em português. De uma parte, o alcance da produção das áreas de Ciências Sociais e Humanidades se vê limitado em função de dificuldades de tradução de termos e expressões locais 18. De outra parte, o fato de a grande maioria dos estudos cientométricos utilizar como referência bases de dados internacionais, fortemente centradas na produção em língua inglesa, contribui para a invisibilidade da produção em CSHS 19.

Para encerrar essa seção, cabe destacar o debate envolvendo a comparação entre duas modalidades ou vias de publicação: artigo e livro. Este último foi especialmente enaltecido por alguns entrevistados com base em argumentos que reconhecem nos livros uma alternativa que atende melhor as necessidades da área de Ciências Sociais em Saúde. Foram ressaltados aspectos de forma, notadamente, a possibilidade de produzir textos mais longos e com maior liberdade na estrutura narrativa, de processo, a exemplo da oportunidade de desenvolver um trabalho mais artesanal, sem deixar de lado reflexões de ordem epistemológica ou política.

"O livro abriu uma fonte de publicação importante para as Ciências Humanas e Sociais que tradicionalmente têm essa forma de publicação, por excelência. Algumas áreas não consideram isso publicação, se tiver dez livros, isso não vai me colocar no ranking. O artigo segue simbolicamente mais valorizado, apesar da pontuação do livro, mas não reverteu o aspecto simbólico do artigo, ainda, por conta da visão de mundo e da colonização, e eu vejo que é uma relação iníqua. Nós temos uma iniquidade imensa, né? Se eu trabalho, por exemplo, o caso clínico, eu publico em uma página e meia de uma revista como Clinics, como Healthcare, por exemplo, e ela vai valer muito mais do que um trabalho em que eu teorizei, fui a campo, interpretei, construí categorias” (GI8).

No tocante à dimensão política, é importante registrar que a luta pela valorização da publicação na forma de livro e capítulos de livro, por parte de docentes e pesquisadores das CSHS, encabeçada pela comissão da área da Abrasco intensificou-se a partir de meados do ano 2000. Alguns dos integrantes da comissão tiveram papel destacado nas comissões criadas pela CAPES para construir o Qualis Livro, o qual já vigorou nas últimas avaliações. Embora ainda seja uma ferramenta em construção e careça de aperfeiçoamento, já se identificam melhoras na avaliação desse tipo de produção bibliográfica. Assim mesmo, o livro segue ocupando uma posição secundária ou menos valorizada do que os artigos (quan- 
do publicados em periódicos de grande impacto) nos processos que envolvem julgamento de mérito acadêmico ou, melhor dito, de produtividade científica.

\section{O sistema de avaliação da pós-graduação, o "produtivismo" e as repercussões para a área de CSHS}

Nessa seção, exploramos a visão dos pesquisadores da área sobre o papel atribuído à publicação científica no conjunto dos parâmetros adotados pela avaliação CAPES e seus reflexos não apenas no processo de credenciamento de docentes, mas também no processo de publicação e na qualidade dos produtos gerados.

Características e efeitos da avaliação CAPES para a pós-graduação em Saúde Coletiva, em especial para os docentes/pesquisadores das CSHS, foram alvos de críticas contundentes. Alguns entrevistados ressaltaram, precisamente, os efeitos deletérios relacionados com a configuração e a sustentabilidade dos programas e recuos na institucionalização da área (CSHS). Foi recorrente também a alusão à perda de qualidade e de originalidade das publicações, além de outras questões relevantes, como a questão da competitividade e as repercussões dos parâmetros de avaliação para a progressão funcional dos docentes:

"Você não tem opção, estará eliminado e ponto final, não tem conversa, produtividade é o que a CAPES diz que é produtividade e ponto final. Então, é uma coisa terrivel... (...) Tem toda uma série de efeitos colaterais perversos de espremer os alunos para que eles produzam artigos, nas disciplinas de pós, toda uma pressão exacerbada, desnecessária que compromete, muitas vezes, a qualidade das pesquisas" (GI3).

"Então, você tem uma lógica competitiva muito grande, uma competição muito grande entre os pares né, que, às vezes, chega a ser predatória mesmo né?! (...) nesse contexto, você também vê muito... cada vez mais do mesmo, cada vez mais reproduções, quer dizer, não é possível que a pessoa tenha tanta novidade assim pra publicar e pra dizer em dez artigos novos por ano, não é possível isso eu não consigo acreditar!" (GN5).

A preocupação com os "efeitos colaterais" do sistema de avaliação da pós-graduação brasileira já havia sido apontada por Horta \& Moraes 20, quando chamaram a atenção para o que denominaram de "círculo vicioso". Uma alusão ao fato de que os docentes de programas com conceitos mais elevados dedicavam a maior parte de seu tempo à produção científica, notadamente publicações, em detrimento de outras atividades, com destaque para a orientação, dado que se refletia em um número relativamente baixo de titulados. A lógica se invertia dentre aqueles vinculados aos programas com notas mais baixas, os quais concentravam grande parte de sua carga horária à orientação, pressionados pela necessidade de reduzir o tempo de titulações dos discentes, liberando assim as bolsas para as novas turmas.

Convém lembrar que a avaliação da CAPES abrange tanto a atribuição de conceitos, e consequente definição de credenciamento dos programas de pós-graduação do Brasil, quanto a definição do Qualis Periódicos e Qualis Livro e nas diversas áreas de conhecimento. Nesse sentido, as distorções ou iniquidades produzidas ou incrementadas pelo sistema não se limitam às diferenças entre os docentes em função da nota de seus respectivos programas. No caso da Saúde Coletiva, acentuam-se as iniquidades entre os três eixos disciplinares que integram o campo: Epidemiologia; Política, Planejamento e Gestão; e CSHS. Com efeito, dentre os limites atribuídos aos critérios vigentes de avaliação da produção científica, são enfatizados, entre os entrevistados, aspectos que tratam especificamente das especificidades da área - modos de atuação, perfil dos produtos etc.

"O Qualis é um problema recente e que impede aventuras interdisciplinares. Por quê? Porque vai depender do Qualis da área o meu valor como pesquisadora. Então, se eu vou pra Medicina 1, na clínica médica, onde o Cadernos de Saúde Pública, que é uma revista A2 na nossa área, é considerado Qualis C [B2]. Eé difícil publicar nos Cadernos! (...) Então, o que é que acontece? Eles podem gostar de mim, eles podem aceitar o enfoque, eles podem fazer parceria em projeto, mas, para eu entrar no corpo permanente, é impossível porque eu derrubo o programa deles, uma vez que eu não publique em periódicos que são considerados ciência para eles" (GI8).

“...O próprio processo de produção de conhecimento é diferente, a velocidade, a maturação de resultados se você pensar, por exemplo, quanto tempo você leva pra fazer uma pesquisa na área de Ciências Sociais e Humanas e amadurecer e refletir etc. (...) Enfim, tem um processo de produção de conhecimento que é diferente e não é valorizado e não é reconhecido" (GN5). 
Encontramos, entre os entrevistados, uma visão mais radical, cujo posicionamento não se centra em defender parâmetros mais justos para avaliar a produção da área de CSHS. Reside, antes, na recusa a colocar a publicação em primeiro plano no bojo da prática acadêmica. Trata-se de uma posição que emana de um docente/pesquisador para a qual as práticas de pesquisa, ensino e ação colaborativa junto à sociedade devem estar sempre articuladas, prevalecendo o interesse dessa última; um perfil relativamente raro entre os docentes credenciados atualmente nos programas de pós-graduação em Saúde Coletiva:

"Olha, publicar pra nós é um desafio muito distinto do que é pros outros grupos porque a forma como a gente organiza o processo de trabalho no grupo pensando nessas três dimensões da formação, da produção de conhecimento e da colaboração é muito distinta dos outros grupos de pesquisa, né? Nós temos uma boa parte do nosso tempo acadêmico dedicado à presença nos territórios, em reuniões com os movimentos sociais (...). A gente considera isso um compromisso ético da pesquisa, então, a gente gasta tempo e recursos da pesquisa na construção disso no processo dialógico com os sujeitos locais, com os movimentos etc. (...) e isso não é reconhecido na academia" (GI4).

O depoimento acima resgata, sobretudo, o princípio da autonomia, um atributo essencial do trabalho intelectual, como bem assinalaram Luz 10 e Loyola 9. A autonomia, seja para definir prioridades ou para escolher o que pesquisar, aliada ao tempo, requerido para produzir conhecimentos originais e densos em CSHS, são apontados, por ambas as autoras, como os elementos mais atingidos pela lógica produtivista/quantitativa.

Quanto ao Qualis Periódicos, cujos critérios foram questionados no depoimento anterior e muitos outros colhidos na pesquisa, uma vez instituído, ele passou a "atuar" como um artefato com forte influência nas práticas e nos processos acadêmicos. Corresponde assim ao que Latour 11 (p. 65) denominou de atores não humanos ou mediadores que "transformam, traduzem, distorcem e modificam o significado ou os elementos que supostamente veiculam".

Em sintonia com Mol 12, quando se analisa a dinâmica das relações ensejadas no contexto acadêmico abordado pela pesquisa, confirma-se a pertinência de levar-se em conta, para além das associações e de colaborações entre os atores, outros elementos que incidem sobre as relações implicadas nas redes de produção de conhecimento e que podem produzir choques, tensões, inclusões ou exclusões. Os critérios em voga para o credenciamento (ou sua renovação) nos programas de pós-graduação em Saúde Coletiva são bons exemplos de elementos causadores de tensão no universo acadêmico investigado, sendo apontados ainda como um fator determinante para incluir ou excluir docentes e pesquisadores das CSHS da atividade acadêmica plena.

\section{Considerações finais}

Os resultados da pesquisa apontam o crescimento da produção científica e o dinamismo da área de CSHS, mas, ao mesmo tempo, revelam aspectos que preocupam, especialmente, no que diz respeito ao impacto da avaliação CAPES sobre a área.

Os pesquisadores entrevistados mostraram insatisfação com vários aspectos do processo de publicação científica, tal como a falta de abertura de algumas revistas da Saúde Coletiva para especificidade da forma de produção nas CSHS, a pouca abertura para abordagens intertransdisciplinares, os critérios formais de apresentação de texto e o número reduzido de revistas da subárea nos estratos superiores do Qualis. A avaliação CAPES foi objeto de críticas por parte dos pesquisadores por conta da pressão sobre o processo de publicação que pode levar à busca da quantidade em detrimento da originalidade e qualidade dos produtos, além de não levar em conta as diferenças nos tempos e nos processos de produção entre as áreas que compõem a Saúde Coletiva.

O fato de o aumento da produção bibliográfica não ter sido acompanhado pelo aumento do número de docentes credenciados nos programas de pós-graduação da área, especialmente levando em conta a grande expansão do número de programas de Saúde Coletiva no período, pode ser um indício da dificuldade dos docentes da área de se credenciarem nos programas de pós-graduação em virtude da crescente exigência de produtividade. A se confirmar essa tendência, é a própria interdisciplinaridade da Saúde Coletiva que ficará prejudicada. 
No momento em que escrevemos essas linhas, o Qualis Periódicos passa por grande modificação na difícil tentativa de construção de um Qualis único para todas as áreas, cujo resultado ainda terá de ser avaliado. Nos últimos anos, tem aumentado a percepção da constatação de que o atual sistema de avaliação está esgotado e de que é necessário avançar em direção a uma avaliação mais qualitativa que desarme a corrida produtivista e foque na qualidade, originalidade e impacto social dos produtos.

\section{Colaboradores}

J. A. B. Iriart participou da produção e análise dos dados e redação do artigo. L. A. B. Trad participou da elaboração do projeto, produção e análise dos dados e redação do artigo.

\section{Informações adicionais}

ORCID: Jorge Alberto Bernstein Iriart (0000-00029518-1240); Leny Alves Bomfim Trad (0000-00028762-4320).

\section{Agradecimentos}

Aos pesquisadores da área de CSHS que aceitaram participar do estudo, ao CNPq pelo apoio financeiro à pesquisa e pelas bolsas de produtividade para os dois autores e a Natanael Vítor Sobral pela importante contribuição na extração de dados do ScriptLattes e cadernos de avaliação da CAPES.

\section{Referências}

1. Coordenação de Aperfeiçoamento de Pessoal de Nível Superior. Documento de área. Saúde Coletiva, 2016. https://www.capes.gov. br/images/documentos/Documentos_de area_2017/22_SCOL_docarea_2016.pdf.pdf (acessado em 28/Mar/2019).

2. Loyola MA. O lugar das Ciências Sociais na Saúde Coletiva. Saúde Soc 2012; 21:9-14.

3. Iriart JAB, Deslandes SF, Martin D, Camargo Jr. KR, Carvalho MS, Coeli CM. A avaliação da produção científica nas subáreas da Saúde Coletiva: limites do atual modelo e contribuições para o debate. Cad Saúde Pública 2015; 31:2137-47.

4. Martin D, Montanari PM, Pereira PPG, Hamburguer FG, Silveira C. As contribuições das Ciências Sociais e Humanas no campo da Saúde Coletiva: vinte anos da revista Interface Comunicação, Saúde, Educação. Interface (Botucatu) 2018; 22:1029-42.

5. Trad LAB. Temas e enfoques contemporâneos nas Ciências Sociais e Humanas no Brasil: expressões e tendências refletidas no $\mathrm{V}$ congresso da área. Cad Saúde Pública 2012; 28:2373-9.

6. Canesqui AM. Produção científica das Ciências Sociais e Humanas em Saúde e alguns significados. Saúde Soc 2012; 21:15-23.

7. Russo JA, Carrara S. Sobre as Ciências Sociais na Saúde Coletiva com especial referência à Antropologia. Physis (Rio J.) 2015; 25:467-84.

8. Camargo Jr. KR, Coeli CM, Caetano R, Maia VR. Produção intelectual em Saúde Coletiva: epistemologia e evidências de diferentes tradições. Rev Saúde Pública 2010; 44:394-8.

9. Loyola MA. A saga das Ciências Sociais na área da Saúde Coletiva: elementos para reflexão. Physis (Rio J.) 2008; 18:251-75.

10. Luz MT. Prometeu acorrentado: análise sociológica da categoria produtividade e as condições atuais da vida acadêmica. Physis (Rio J.) 2005; 15:39-57.

11. Latour B. Reagregando o social: uma introdução à Teoria do Ator-Rede. Salvador: Edufba/ Bauru: Edusc; 2012. 
12. Mol A. Actor-Network Theory: sensitive terms and enduring tensions. Kolner $\mathrm{Z} \mathrm{Soz}$ Sozpsychol 2010; 50:253-69.

13. Ianni A, Spadacio C, Barboza R, Alves OSF, Viana SDL, Rocha AT. Trajetórias profissionais na constituição das Ciências Sociais e Humanas em Saúde na Abrasco. Physis (Rio J.) 2014; 24:1315-35.

14. Minayo MCS. Pós-graduação em Saúde Coletiva de 1997 a 2007: desafios, avanços e tendências. Ciênc Saúde Colet 2010; 15:1897-907.

15. Viacava F, Ramos C. Difusão da produção científica dos cursos de pós-graduação em saúde coletiva. Ciênc Saúde Colet 1997; 2:142-53.

16. Costa NR. A avaliação da produção intelectual e o declínio da interdisciplinaridade na Saúde Coletiva. Physis (Rio J.) 2012; 22:681-99.

17. Katz JS, Martin BR. What is research collaboration? Res Policy 1997; 26:1-18.
18. Hoekman J, Frenken K, Tijssen RJW. Research collaboration at a distance: changing spatial patterns of scientific collaboration within Europe. Res Policy 2010; 39:662-73.

19. Sidone OJG, Haddad EA, Mena-Chalc JP. A ciência nas regiões brasileiras: evolução da produção e das redes de colaboração científica. TransInformação 2016; 28:15-31.

20. Horta JSB, Moraes MCM. O sistema CAPES de avaliação da pós-graduação: da área de Educação à grande área de Ciências Humanas. Rev Bras Educ 2005; 30:95-116. 


\section{Abstract}

This article aims to establish a profile of research production by professors in the field of Human and Social Sciences in Health (HSSH) in graduate studies programs in Public Health, focusing on the period from 2004 to 2012 (three consecutive three-year of the assessment by the Brazilian Graduate Studies Coordinating Board - CAPES), as well as the researchers' views of the publishing process and the main challenges. The data sources were the CAPES assessment notebooks from 2004 to 2012 and the research output recorded in the Curriculum Lattes database for 176 professors from the HSSH field accredited in the graduate studies programs in Public Health in the same period, obtained from the ScriptLattes tool. Online questionnaires were answered anonymously by 59 researchers, besides in-depth semi-structured interviews with 19 researchers from different generations, in addition to incorporating the authors' perceptions from both data sources on the field's recent situation. Research output in $\mathrm{HSSH}$ increased by $60.49 \%$ in the production of articles and $25.22 \%$ in the production of books in the period studied (62.36\% of the research output was published in the form of articles). However, the number of researchers did not increase during the period, which may be explained by the difficulty in accreditation in the graduate studies programs due to growing pressure to publish. Researchers from the field expressed dissatisfaction with various aspects of the science publishing process and the effects of CAPES assessment, including the push for "productivism", overlooking differences between areas in research production tempos and processes, a situation that can compromise Public Health's inherent interdisciplinarity.

Social Sciences; Humanities; Research; Evaluation of Research Programs and Tools; Scientific Publication Indicators

\section{Resumen}

El objetivo de este artículo es trazar el perfil de la producción científica de docentes del área de las Ciencias Sociales y Humanas en Salud (CSHS), en los programas de posgrado en Salud Colectiva, centrándose en el período de 2004 a 2012 (tres trienios de la evaluación de la Coordinación de Perfeccionamiento de Personal de Nivel Superior - CAPES), así como la visión de los investigadores sobre el proceso de publicación y sus principales desafíos. Se utilizaron como fuentes de datos, los cuadernos de evaluación de la CAPES de 2004 a 2012, y la producción bibliográfica registrada en el Curriculum Lattes de 176 profesores del área de CSHS, acreditados en los programas de porgrado en Salud Colectiva durante el mismo período, extraída a través de la herramienta ScriptLattes. También se realizaron cuestionarios on line, respondidos de forma anónima por 59 investigadores, $y$ entrevistas semiestructuradas en profundidad, realizadas con 19 investigadores de diferentes generaciones, incorporando, también a través de ambas fuentes, la percepción de los actores sobre la situación más reciente del área. La producción científica en CSHS aumentó un 60,49\% en la producción de artículos y un 25,22\% en la producción en libros durante el periodo estudiado. Un 62,36\% de la producción científica se publicó en forma de artículo. El número de investigadores, no obstante, no aumentó durante el periodo, lo que puede estar relacionado con la dificultad de acreditación en los programas de posgrado, debido a las crecientes exigencias de producción. Los investigadores del área mostraron su insatisfacción con varios aspectos del proceso de publicación científica, y con los efectos de la evaluación CAPES, entre los cuales el incentivo al "productivismo" y la desconsideración de las diferencias en los tiempos y en los procesos de producción entre las áreas, lo que puede llegar a comprometer la propia interdisciplinaridad que caracteriza la Salud Colectiva.

Ciencias Sociales; Humanidades; Investigación;

Evaluación de Programas e Instrumentos

de Investigación; Indicadores de Producción

Cientifica
Recebido em 07/Mai/2019

Versão final reapresentada em 11/Out/2019

Aprovado em 11/Nov/2019 